\title{
Clinical effects of nursing intervention on severe patients in the respiratory department.
}

\author{
Guoli Long ${ }^{1}$, Lei Yue ${ }^{2 *}$, Zongyin Peng ${ }^{1}$, Guoying Xiong ${ }^{3}$, Yumei Li $^{3}$ \\ ${ }^{1}$ Department of the Intensive Care Unit, East Branch, Sichuan Academy of Medical Sciences and Sichuan Provincial \\ People's Hospital, Chengdu, Sichuan, PR China \\ ${ }^{2}$ Department of Emergency, East Branch, Sichuan Academy of Medical Sciences and Sichuan Provincial People's \\ Hospital, Chengdu, Sichuan, PR China \\ ${ }^{3}$ Department of Nursing, East Branch, Sichuan Academy of Medical Sciences and Sichuan Provincial People's Hospital, \\ Chengdu, Sichuan, PR China
}

\begin{abstract}
Objective: This study aimed is to discuss the clinical effects of nursing intervention on severe patients in a respiratory department.

Methods: Eighty-four severe patients admitted in the respiratory department in our hospital from January 2016 to September 2017 were selected and categorized into the control $(n=42)$ and intervention groups $(n=42)$ through random number table method. The control group was provided with conventional intervention, and the intervention group was treated with nursing intervention. The nursing effect, blood indexes, hours of respirator use, observation time in the Intensive Care Unit (ICU), occurrence rate of adverse event, and nursing satisfaction of the two groups were compared.

Results: The total nursing efficiencies of the intervention and control groups were $92.9 \%$ and $76.2 \%$, which showed significant difference $(\mathbf{P}<\mathbf{0 . 0 5})$. The intervention group was superior to the control group in terms of heart rate, respiratory rate, arterial partial pressure of oxygen, arterial partial pressure of carbon dioxide, hours of respirator use, and observation time in the ICU $(P<0.05)$. The occurrence rate of adverse events of the intervention group was $4.8 \%$, which was significantly lower than that of the control group $(\mathbf{1 9 . 0 \%})(\mathbf{P}<\mathbf{0 . 0 5})$. The nursing satisfaction of the intervention group $(\mathbf{9 5 . 2 \%})$ was exceedingly higher than that of the control group $(\mathbf{8 1 . 0 \%})(\mathbf{P}<0.05)$.

Conclusions: Compared with conventional intervention, nursing intervention presented more outstanding clinical effects to severe patients in the respiratory department. Nursing intervention can not only improve the blood indexes of patients but also reduce the occurrence rate of adverse events and increase the nursing satisfaction of patients. Nursing intervention was associated with safety and reliability. Therefore, nursing intervention has promising clinical application and should be promoted.
\end{abstract}

Keywords: Respiratory department, Nursing intervention, Nursing efficacy, Blood indexes, Adverse event.

Accepted on November 29, 2017

\section{Introduction}

The incidence rate of respiratory system diseases increases every year because of the rapid social development and the intensified environmental pollution [1]. Respiratory system disease is a common disease in clinics that is characterized by long duration, repeated occurrence, and abundant complications [2]. Patients with severe respiratory system diseases typically manifest acute attacks and severe conditions. Such diseases might deteriorate and even cause respiratory failure and deaths if no effective intervention is implemented in time [3]. Relevant studies have reported that nursing intervention can improve the clinical effect and prognosis of patients being treated for severe respiratory system diseases
[4]. Thus, 84 severe patients admitted in the respiratory department in our hospital from January 2016 to September 2017 were chosen to assess the clinical effects of nursing intervention.

\section{Information and Method}

\section{General information}

In this study, 84 severe patients admitted in the respiratory department in our hospital from January 2016 to September 2017 were chosen as the study objects and divided into the control $(n=42)$ and intervention groups $(n=42)$ through random number table method. The control group consisted of 20 
females and 22 males who had an age range of 20-83 y old (average: $50.1 \pm 5.1$ ). The control group included 19 cases of chronic obstructive pneumonia, 10 cases of chronic bronchitis, eight cases of bronchial asthma, four cases of bronchiectasia, and one case of lung cancer. The intervention group consisted of 19 females and 23 males who had an age range of 22-82 y old (average: $50.0 \pm 5.0$ ). The intervention group included 20 cases of chronic obstructive pneumonia, 10 cases of chronic bronchitis, eight cases of bronchial asthma, three cases of bronchiectasia, and one case of lung cancer. A statistical analysis was conducted on the general information between the two groups by using SPSS 22.0, and no significant difference $(\mathrm{P}>0.05)$ was found. All respondents volunteered to participate in this study and signed Informed Consent forms. This study conformed to the requirements of Ethics Committee.

\section{Methods}

The control group was provided with conventional intervention. That is, common nursing services were offered strictly in accordance with the doctor's advice. By contrast, the intervention group was treated with nursing intervention.

Psychological intervention was given to patients who easily manifest unhealthy emotions due to long treatment time and slow effect. Depression and coughs during the treatment will influence the daily life of patients. Therefore, the nursing staff shall positively communicate with the patients, evaluate their psychological states, adopt appropriate psychological counselling based on the actual situations of the patients, and relieve the unhealthy emotions of patients, thereby increasing their compliance to the treatment. In addition, the nursing staff shall discuss successful cases to patients and enhance their confidence toward the treatment.

Diet intervention is given by asking the patients to eat foods rich in proteins and energies without blindly increasing their food intake. Instead, the patients shall follow the principle of having more meals a day but with less food at each meal. The patients shall eat slowly.

Oxygen uptake intervention: During oxygen uptake, the pipeline and mask smoothness shall be examined carefully. Secreta must be eliminated in time to ensure the smooth oxygen uptake and respiration of the patients. The proper body position shall be observed during expectoration, and the patients shall drink more water to dilute the sputum and avoid phlegm obstruction.

Oral intervention: The patients must take various antiinflammatory medications, which can easily generate abundant bacteria on the mouth, thus causing an imbalanced microbial community structure and oral infection. Therefore, the nursing staff shall supervise and ensure that the patients take the proper dose of medicines on time to ensure medication safety, reduce the occurrences of adverse events, and ensure therapeutic effect.

Environmental intervention: The nursing staff shall create a comfortable and quite inpatient ward environment, ventilate the room regularly, ensure adequate sunlight, maintain appropriate indoor temperature and humidity, and enhance the regular disinfection to facilitate the quick rehabilitation of patients.

\section{Observation indexes}

The nursing effect, blood indexes, hours of respirator use, observation time in the ICU, occurrence rate of adverse event, and nursing satisfaction of the two groups were compared. The blood indexes were $\mathrm{HR}, \mathrm{RR}, \mathrm{PaO}_{2}$, and $\mathrm{PaCO}_{2}$. The adverse events were infection and cardiac arrest.

\section{Evaluation standards of nursing effect}

The nursing effect was evaluated based on the rehabilitation conditions of the patients. The nursing effect is considered significantly effective if the clinical symptoms disappear, and all indexes are normal. The nursing effect is effective if the clinical symptoms are relieved to some extent, and the indexes tend to be stable. The nursing effect is ineffective if the patients fail to achieve the abovementioned standards. The total efficiency is the sum of the significantly effective percentage and the effective percentage.

\section{Statistical analysis}

The observation data of the two groups were analysed by using SPSS22.0. The enumeration data (i.e., total nursing efficiency, occurrence rate of adverse events, and degree of satisfaction) were expressed as percentages and examined by using chisquare test. The measurement data (i.e., $\mathrm{HR}, \mathrm{RR}, \mathrm{PaO}_{2}, \mathrm{PaCO}_{2}$, time of respirator use, and observation time in the ICU) were expressed as $\overline{\mathrm{x}} \pm \mathrm{s}$ and examined by using t-test. $\mathrm{P}<0.05$ indicated a significant difference between the two groups.

\section{Results}

\section{Nursing effect}

The total nursing efficiencies of the intervention and control groups were $92.9 \%$ and $76.2 \%$, which showed significant difference $(\mathrm{P}<0.05)$ (Table 1).

\section{Blood indexes}

Significant differences were observed between the intervention and control groups in $\mathrm{HR}, \mathrm{RR}, \mathrm{PaO}_{2}$, and $\mathrm{PaCO}_{2}(\mathrm{P}<0.05)$ (Table 2).

\section{Hours of respirator use and observation time in ICU}

The intervention group was superior to the control group in terms of hours of respirator use and observation time in the ICU $(\mathrm{P}<0.05)$ (Table 3).

\section{Occurrence of adverse event}

The occurrence rate of adverse events of the intervention group was $4.8 \%$, which was significantly lower than that of the 
control group $(19.0 \%)(\mathrm{P}<0.05)$. The results are shown in Table 4.

\section{Nursing satisfaction}

The nursing satisfaction of the intervention group (95.2\%) was exceedingly higher than that of the control group $(81.0 \%)$ $(\mathrm{P}<0.05)$. The results are shown in Table 5 .

Table 1. Comparison of nursing efficiency between the two groups ( $n$ (\%)).

\begin{tabular}{lllll}
\hline Groups & $\begin{array}{l}\text { Significant } \\
\text { effective }\end{array}$ & Effective & Ineffective & $\begin{array}{l}\text { Total } \\
\text { efficiency }\end{array}$ \\
\hline $\begin{array}{l}\text { Intervention } \\
(n=42)\end{array}$ & $17(40.5)$ & $22(52.4)$ & $3(7.1)$ & $39(92.9)$ \\
\hline $\begin{array}{l}\text { Control } \\
(n=42)\end{array}$ & $13(31.0)$ & $19(45.2)$ & $10(23.8)$ & $32(76.2)$ \\
\hline$X^{2}$ & & & 4.4593 \\
\hline$P$ & & & 0.0347 \\
\hline
\end{tabular}

Table 2. Comparison of blood indexes between the two groups $(\bar{x} \pm s)$.

\begin{tabular}{lllll}
\hline Groups & $\begin{array}{l}\mathrm{HR} \\
\mathbf{m i n})\end{array}$ & $\begin{array}{c}\text { (time/ } \\
\mathrm{RR} \\
\mathbf{m i n})\end{array}$ & $\begin{array}{c}\text { (time/ } \\
\mathrm{PaO}_{2} \\
(\mathbf{m m H g})\end{array}$ & $\begin{array}{l}\mathrm{PaCO}_{2} \\
(\mathbf{m m H g})\end{array}$ \\
\hline $\begin{array}{l}\text { Intervention } \\
(\mathrm{n}=42)\end{array}$ & $90.1 \pm 7.0$ & $20.2 \pm 2.5$ & $93.5 \pm 6.7$ & $86.2 \pm 4.5$ \\
\hline $\begin{array}{l}\text { Control } \\
(\mathrm{n}=42)\end{array}$ & $96.9 \pm 5.8$ & $26.4 \pm 2.3$ & $63.5 \pm 3.7$ & $76.2 \pm 4.7$ \\
\hline $\mathrm{t}$ & 4.8477 & 11.8280 & 25.4021 & 9.9597 \\
\hline $\mathrm{P}$ & 0.0000 & 0.0000 & 0.0000 & 0.0000 \\
\hline
\end{tabular}

Table 3. Comparison of hours of respirator use and observation time in ICU between the two groups $(\bar{x} \pm s)$.

\begin{tabular}{lll}
\hline Groups & $\begin{array}{l}\text { Hours of respirator use } \\
(\mathrm{h})\end{array}$ & $\begin{array}{l}\text { Observation } \\
\text { ICU (d) }\end{array}$ \\
\hline Intervention $(\mathrm{n}=42)$ & $209.1 \pm 81.3$ & $6.0 \pm 3.6$ \\
\hline Control $(\mathrm{n}=42)$ & $312.3 \pm 84.6$ & $11.0 \pm 5.0$ \\
\hline $\mathrm{t}$ & 5.7001 & 5.2593 \\
\hline $\mathrm{P}$ & 0.0000 & 0.0000 \\
\hline
\end{tabular}

Table 4. Comparison of occurrence rate of adverse events between the two groups $(n \%)$.

\begin{tabular}{llll}
\hline Groups & Infection & Cardiac arrest & Total occurrence rate \\
\hline Intervention $(\mathrm{n}=42)$ & $1(2.4)$ & $1(2.4)$ & $2(4.8)$ \\
\hline Control $(\mathrm{n}=42)$ & $5(11.9)$ & $3(7.1)$ & $8(19.0)$ \\
\hline $\mathrm{X}^{2}$ & & & 4.0864 \\
\hline $\mathrm{P}$ & & & 0.0432 \\
\hline
\end{tabular}

Table 5. Comparison of nursing satisfaction between the two groups $(n(\%))$.

\begin{tabular}{lllll}
\hline Groups & $\begin{array}{l}\text { Very } \\
\text { satisfying }\end{array}$ & Satisfying & Unsatisfying & $\begin{array}{l}\text { Degree of } \\
\text { satisfaction }\end{array}$ \\
\hline $\begin{array}{l}\text { Intervention } \\
(\mathrm{n}=42)\end{array}$ & $18(42.9)$ & $22(52.4)$ & $2(4.8)$ & $40(95.2)$ \\
\hline $\begin{array}{l}\text { Control } \\
(\mathrm{n}=42)\end{array}$ & $13(31.0)$ & $21(50.0)$ & $8(19.0)$ & $34(81.0)$ \\
\hline $\mathrm{X}^{2}$ & & & 4.0864 \\
\hline $\mathrm{P}$ & & 0.0432 \\
\hline
\end{tabular}

\section{Discussion}

Patients with severe respiratory system diseases manifest acute attacks and severe conditions, resulting in long treatments and high occurrence rates of secondary infections, which further prolong the treatment time of patients [5]. Consequently, patients develop unhealthy emotions, including anxiety, fear, and pessimism, all of which influence the treatment [6]. Thus, the implementation of relevant nursing intervention in clinical treatments must be enhanced to reduce the occurrence of secondary infections and accelerate the rehabilitation of patients [7].

Nursing intervention is a recently emerging nursing mode that imposes very high requirements on the nursing staff. The nursing staff shall implement comprehensive nursing interventions, observe psychological changes in the patients, and provide appropriate counselling to relieve the pains of the patients, increase their compliance in treatment, and improve the therapeutic effect [8].

In recent years, nursing intervention has been widely used in patients with severe respiratory system diseases. It not only offers comprehensive nursing services to patients (e.g., psychological intervention, diet intervention, oxygen uptake intervention, sputum excretion, oral and environmental cleaning) but also relieves the clinical symptoms of patients and creates a comfortable therapeutic environment for the patients $[9,10]$. Nursing intervention improves the treatment experience of the patients, ensures their safety, and increases their degree of satisfaction. This study found that the intervention group was superior to the control group in terms of total nursing efficiency, $\mathrm{HR}, \mathrm{RR}, \mathrm{PaO}_{2}, \mathrm{PaCO}_{2}$, hour of respirator use, observation time in the ICU, occurrence rate of adverse events, and degree of satisfaction. The significant differences between the two groups $(\mathrm{P}<0.05)$ reveal that nursing intervention can improve the clinical effect and blood indexes of patients with severe respiratory system diseases, reduce the occurrence rate of adverse events, shorten the hours of respirator use and observation time in the ICU, and increase the degree of nursing satisfaction. Nursing intervention has promising clinical application potential and is consistent with the findings in literature.

\section{Conclusion}

Compared with conventional intervention, nursing intervention presented more outstanding clinical effects to patients with severe respiratory system diseases. It can not only improve the 
blood indexes of patients but also reduce the occurrence rate of adverse events and increase the nursing satisfaction of patients. Nursing intervention was associated with safety and reliability. Therefore, nursing intervention has promising clinical application and should be promoted.

\section{References}

1. Sanchez JL, Cooper MJ, Myers CA, Cummings JF, Vest KG, Russell KL, Sanchez JL, Hiser MJ, Gaydos CA. Respiratory infections in the U.S. Military: recent experience and control. Clin Microbiol Rev 2015; 28: 743-800.

2. Khanehmasjedi M, Miresmaili A, Jafari S, Khanehmasjedi S. Comparison of the soft tissue orthodontic analysis measurements between conventional lateral cephalograms and CBCT derived lateral cephalograms. Biomed Res India 2017; 28: 1087-1090.

3. Brendish NJ, Malachira AK, Clark TW. Molecular pointof-care testing for respiratory viruses versus routine clinical care in adults with acute respiratory illness presenting to secondary care: a pragmatic randomised controlled trial protocol (ResPOC). BMC Infect Dis 2017; 17: 128.

4. Arain MI, Ghoto MA, Dayo A. Evaluation of awareness regarding hypertension and their therapy among hypertensive patients at hospital of Hyderabad, Pakistan. Lat Am J Pharm 2017; 36: 1942-1946.

5. Chan JFW, Lau SKP, To KKW, Cheng VCC, Woo PCY, Yuen KY. Middle East respiratory syndrome coronavirus: another zoonotic betacoronavirus causing SARS-like disease. Clin Microbiol Rev 2015; 28: 465-522.
6. Colak MC, Colak C, Erdil N, Sandal S. Potential risk factors for early large pleural effusion after coronary artery bypass grafting surgery. Biomed Res India 2017; 28: 625-629.

7. Zhao L, Huang X, Hong W, Qiu S, Wang J, Yu L, Zeng Y, Tan X, Zhang F. Slow resolution of inflammation in severe adult dengue patients. BMC Infect Dis 2016; 16: 291.

8. Li M, Zhang XF, Sun G, Bai Y, Liu CH. Co-administration risk between regorafenib and irinotecan during the therapy of lung cancer patients. Lat Am J Pharm 2017; 36: 1796-1800.

9. Chang PE, Goh BBG, Ekstrom V, Ong ML, Tan CK. Low serum albumin predicts early mortality in patients with severe hypoxic hepatitis. World J Hepatol 2017; 9: 959-966.

10. Walkey AJ, Wiener RS. Hospital case volume and outcomes among patients hospitalized with severe sepsis. Am J Respir Crit Care Med 2014; 189: 548-555.

\section{*Correspondence to}

Lei Yue

Department of Emergency

East Branch

Sichuan Academy of Medical Sciences and Sichuan Provincial People's Hospital

PR China 